\section{Incidental Papillary Microcarcinoma of the Thyroid-Further Evidence of a Very Low Malignant Potential: A Retrospective Clinicopathologic Study with up to 30 Years of Follow-up}

\section{TO THE EDITORS:}

As the article by Neuhold et al. indicates, the management of micropapillary carcinoma, particularly that which is incidentally detected, has always been controversial. ${ }^{1}$ The study of the natural course of the disease would be helpful in deciding the aggressiveness of the initial treatment. This information can be obtained from studies with lengthy follow-up periods, such as that of Neuhold et al. To date, few studies have provided such lengthy follow-up., ${ }^{2,3}$ However, once any anticancer treatment is provided to a particular patient in the form of either surgery or radioactive iodine therapy, the natural course of the disease alters and may confound the results. These factors should be examined in detail. Thus, we would like clarification from the authors regarding a few points.

In the study of Neuhold et al., the lymph nodes were clinically palpable in 5 cases; were those lymph nodes central or lateral? Because all other papillary microcarcinomas were diagnosed incidentally, what was the rationale of performing lymph node dissection in $20 \%$ of cases, and which group of lymph nodes was dissected, central or lateral?

In the present series, radioactive iodine was administered in $22 \%$ cases; how were these patients selected for radioactive iodine therapy?
Among four cases of recurrence, in their patient 2, a 38year-old woman who had nonincidentally detected papillary microcarcinoma due to palpable cervical lymph nodes, why was the lymph node dissection not performed in a primary setting?

Similarly, in their patient 3, a 39-year-old woman, the tumor size was 5.5/10.7. What does this imply? The authors mentioned that the World Health Organization definition for papillary microcarcinoma is tumor $\leq 1 \mathrm{~cm}$ in size, a definition that the authors probably followed; why, then, is a tumor $>1 \mathrm{~cm}$ in size included among papillary microcarcinomas?

Finally, what do the authors mean by the term "extended thyroidectomy," and is it recognized by any other authority?

\section{Sudhi Agarwal, Amit Agarwal, and Gyan Chand}

Department of Endocrine and Breast Surgery, Sanjay Gandhi Post Graduate Institute of Medical Sciences, Lucknow, Uttar Pradesh, India

e-mail: sud_soni@rediffmail.com

Published Online: 28 June 2011

(C) Society of Surgical Oncology 2011

\section{REFERENCES}

1. Neuhold N, Schultheis A, Hermann M, Krotla G, Koperek O, Birner P. Incidental papillary microcarcinoma of the thyroidfurther evidence of a very low malignant potential: a retrospective clinicopathological study with up to 30 years of follow-up. Ann Surg Oncol. In press.

2. Hay ID, Hutchinson ME, Gonzalez-Losada T, et al. Papillary thyroid microcarcinoma: a study of 900 cases observed in a 60year period. Surgery. 2008;144:980-7.

3. Noguchi S, Yamashita H, Uchino S, Watanabe S. Papillary microcarcinoma. World J Surg. 2008;32:747-53.

4. Livolsi VA, Saavedra JA. Papillary carcinoma. In: De Lellis RA, Lloyd RV, Heitz PU, Eng C, editors. World Health Organization classification of tumours. Pathology and genetics of tumours of endocrine organs. Lyon, France: IARC Press 2004; p. 57-66. 